\title{
Screening for non-communicable diseases
}

\author{
D. M. Christe ${ }^{1 *}$, S. Vijaya ${ }^{2}$, K. Tharangini ${ }^{2}$
}

\begin{abstract}
${ }^{1}$ Department of Research in Human Reproduction, IOG, National Institute for Research in Human Reproduction Field Unit, Indian Council of Medical Research Chennai, Tamil Nadu, India

${ }^{2}$ Department of Obstetrics and Gynecology, Institute of Obstetrics and Gynecology Chennai, Tamil Nadu, India
\end{abstract}

Received: 07 January 2020

Accepted: 29 January 2020

\section{*Correspondence:}

Dr. D. M. Christe,

E-mail: drdmchriste@gmai.com

Copyright: () the author(s), publisher and licensee Medip Academy. This is an open-access article distributed under the terms of the Creative Commons Attribution Non-Commercial License, which permits unrestricted non-commercial use, distribution, and reproduction in any medium, provided the original work is properly cited.

\begin{abstract}
Background: This study was conducted to enumerate the results of screening for non-communicable diseases in the NCD clinic over a period of one year in a tertiary health centre.

Methods: The results from screening tests conducted in the NCD clinic, for detecting hypertension, diabetes mellitus, breast cancer and cervical cancer, in Government tertiary care Hospital for Women, Chennai, were recorded. The flowchart and screening methods followed were those recommended by the NHM - NPCDCS. Data thus obtained was analyzed using standard statistical methods.

Results: Of 42,519 women screened for common non communicable diseases - hypertension, diabetes mellitus, breast cancer and cervical cancer, nearly $5.55 \%$ women $(n=2359)$ had positive results, for any one of the diseases screened. Of 11,708 women screened for diabetes mellitus and 13,971 screened for hypertension, positive results were found in 856 women and 1,216 women respectively. Around 7,568 women were screened for cervical cancer and 175 women tested positive. A large number of 9,272 women were screened for breast cancer and 112 women had positive results. As per the guidelines, women who tested positive for screening tests were referred to the concerned departments in RGGGH.

Conclusions: Nearly 42,519 women were screened for common non-communicable diseases (NCDs) - hypertension, diabetes mellitus, breast cancer and cervical cancer, and $5.55 \%$ women had positive test results for any one of the diseases screened. The screening revealed, $8.7 \%$ of women had raised blood pressure, $7.31 \%$ had raised blood sugar levels, $1.21 \%$ women had positive screening test results for breast cancer, and $2.31 \%$ women for cervical cancer.
\end{abstract}

Keywords: Breast cancer, Cervical cancer, Diabetes mellitus, Hypertension, Non communicable diseases

\section{INTRODUCTION}

India is experiencing an expeditious health transition with a rising burden of non-communicable diseases (NCD) exceeding the burden of communicable diseases like water-borne or vector-borne diseases, HIV, TB and others. ${ }^{1}$ Non communicable diseases are the major cause of global mortality, contributing to more than $63 \%$ of allcause mortality in the population. ${ }^{2}$ Non communicable diseases also causes considerable loss in potentially productive years of life. Losses due to premature deaths related to non-communicable diseases are also projected to increase over the years. ${ }^{3}$

In order to prevent and control major Non-communicable diseases, NPCDCS was launched in 2010 with focus on strengthening infrastructure, human resource development, health promotion, early diagnosis, management and referral. The recent initiatives under NPCDCS for early detection of diabetes, hypertension and common cancers in the community includes the guidelines for initiating Population-based screening of 
common NCD utilizing the services of the frontlineworkers and health-workers under the existing healthcare system starting from the primary health centers. ${ }^{4}$ Approval for conducting this retrospective analytical study was given by the Institutional Ethics Committee. Consent was not obtained from individual study participants as data was accessed and analyzed from medical records only, maintaining complete patient confidentiality.

Objective of this study was to enumerate the results of screening for non-communicable diseases in the NCD clinic over a period of one year in a tertiary health centre.

\section{METHODS}

This retrospective analytical study was conducted from the data collected over a period of one-year form January 2018 to December 2018. The results from screening tests conducted in the NCD clinic, for detecting hypertension, diabetes mellitus, breast cancer and cervical cancer, in Government tertiary care Hospital for Women, Chennai, were recorded. The flowchart and screening methods followed were those recommended by the NHM NPCDCS. Data thus obtained was analyzed using standard statistical methods. All women attending the NCD clinic, during the study period, formed the study population. All women who were attending the NCD clinic for the first time, during the study period were included in the study and formed the study group. All women who came for follow-up to the NCD clinic were excluded. Women attending the NCD clinic were informed about all the screening procedures and willing women were screened.

\section{Screening for hypertension}

The procedure followed was as given in standard medical text books. Blood pressure was measured over brachial artery, for the women attending the NCD clinic, in a sitting posture, with the BP cuff covering the two-third of upper arm length and the entire girth of the upper arm, at the level of the heart. The criteria for raised blood pressure was, the blood pressure recorded more than or equal to $140 / 90$ $\mathrm{mmHg}$, for women of age $>18$ years and more than $150 / 90$ $\mathrm{mmHg}$ for women of age 60 years and above.

\section{Screening for diabetes mellitus}

Women, aged above 30 years, attending the NCD clinic were screened for diabetes mellitus using random capillary blood glucose value, obtained by finger prick method. Random capillary blood glucose value $>=140$ $\mathrm{mg} / \mathrm{dl}$ is considered as a positive test for screening for diabetes mellitus.

\section{Screening for breast cancer}

Both the breasts were inspected to compare the size, shape and colour. Any swelling or distortion in the breasts, and dimpling, puckering or bulging of the skin was looked for. Nipples were inspected for the position, redness, rash or discharge. The above changes were once again looked for, with both the arms in raised position. Next, with the women in lying down position, both the breasts were palpated with the flat of the palm and repeated with the first few finger pads of the hand using a circular motion about the size of an old one-rupee coin. The entire breast, both right and left was examined from top to bottom and then left to right to detect the presence of any lumps.

\section{Screening for cervical cancer}

The woman was examined in the dorsal lithotomy position. The cervix was visualized under magnavision lens. Any abnormal appearance or discharge from the cervix was noted. After application of 5\% acetic acid on the surface of the cervix, appearance of any white change and areas covered were noted. Cervix with abnormal appearance/discharge, and/or acetowhite changes after application of acetic acid were considered test positive.

Women with positive test results were encouraged to initiate lifestyle changes, by avoiding tobacco use and high salt, encouraging fruits and vegetables intake, and were encouraged moderate physical activity and referred to the respective hypertension, diabetes or breast clinic, at RGGGH for further management. Women with positive tests for cervical cancer screening were referred to colposcopy screening clinic, in the same tertiary centre for further management.

\section{RESULTS}

Of the 42,519 women screened for common non communicable diseases - hypertension, diabetes mellitus, breast cancer and cervical cancer, nearly $5.55 \%$ women $(n=2359)$ had positive results for screening tests done for any one of the diseases screened. Nearly 13,971 women were screened for hypertension in the study period, of which 1,216 women were found to have raised blood pressure. Of 11,708 women screened for diabetes mellitus in the year 2018, 856 women had positive results for the screening tests. Around 7,568 women were screened for cervical cancer in the study year and 175 women had positive test results for screening.

A large number of 9,272 women were screened for breast cancer, of these 112 women had positive test results. As per the NCD guidelines, any women who tested positive for the screening tests for hypertension, diabetes mellitus or breast cancer were referred to the respective hypertension clinic, diabetes clinic or breast clinic, at the Govt. General hospital (RGGGH) for further management. Nearly 175 women with positive tests for cervical cancer screening were referred to colposcopy cervical cancer screening clinic, in the same tertiary centre for further management. 


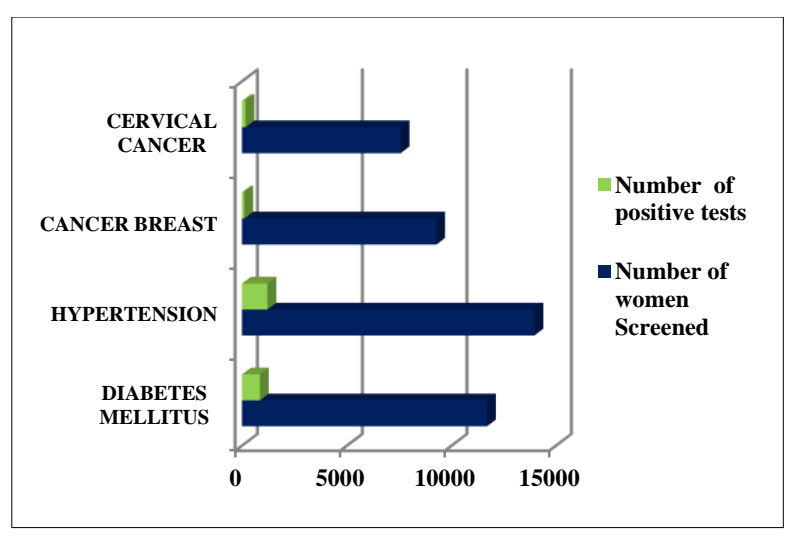

Figure 1: Screening for non-communicable diseases - 2018.

The screening results of the NCD - $8.7 \%$ women had raised blood pressure, $7.31 \%$ had raised blood sugar levels. Nearly $1.21 \%$ women had positive screening test results for cancer breast, $2.31 \%$ women had positive screening test results for cervical cancer (Figure 1).

\section{DISCUSSION}

The screening results of the NCD revealed that $8.7 \%$ women had raised blood pressure, $7.31 \%$ had raised blood sugar levels. Nearly $1.21 \%$ women had positive screening test results for breast cancer, $2.31 \%$ women had positive screening test results for cervical cancer.

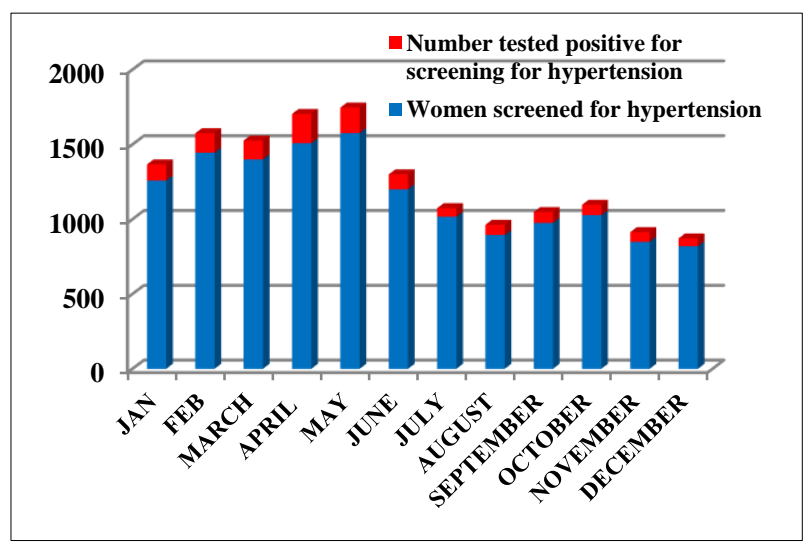

Figure 2: Screening for hypertension - 2018.

The number of women screened for hypertension and the number of women with positive test results month-wise, in the year 2018 (Figure 2).

On comparing the numbers of women who had undergone screening and the numbers of women with positive test results, Authors did not observe any significant variation in the proportional ratio between the number of women screened and the number of women detected with positive test results.

More numbers of attendees were observed in the first six months of the calendar year, from January to June.
Authors observed a decline in the numbers from the month of July and thereafter in the second half of the year, the numbers of women who were screened monthly remained the same. This was comparable, for the screening of women for diabetes mellitus and hypertension in both the monthly and yearly numbers of women screened and the number of women found to be positive for the test results. More studies should be done to identify the causes for the month wise variation in numbers of women screened.

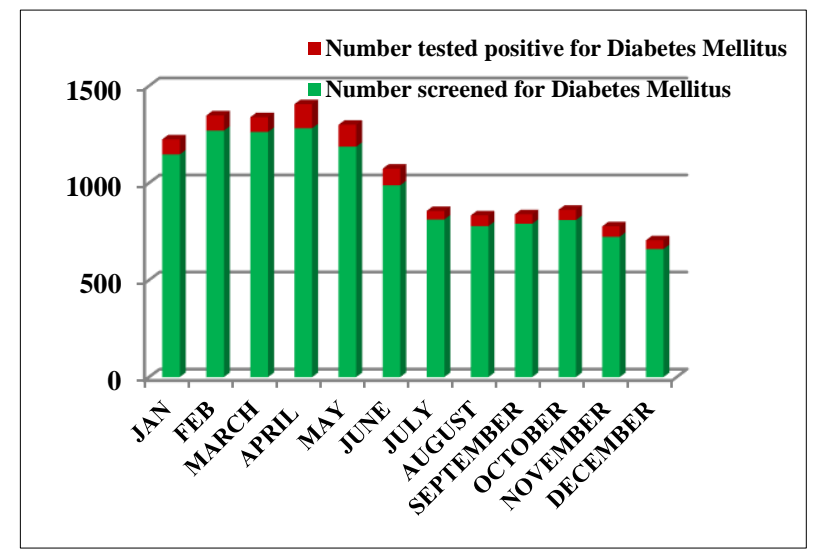

Figure 3: Screening for diabetes mellitus - 2018.

The no. of women screened for diabetes mellitus and the no. of women with positive test results month-wise, in the year 2018 (Figure 3).

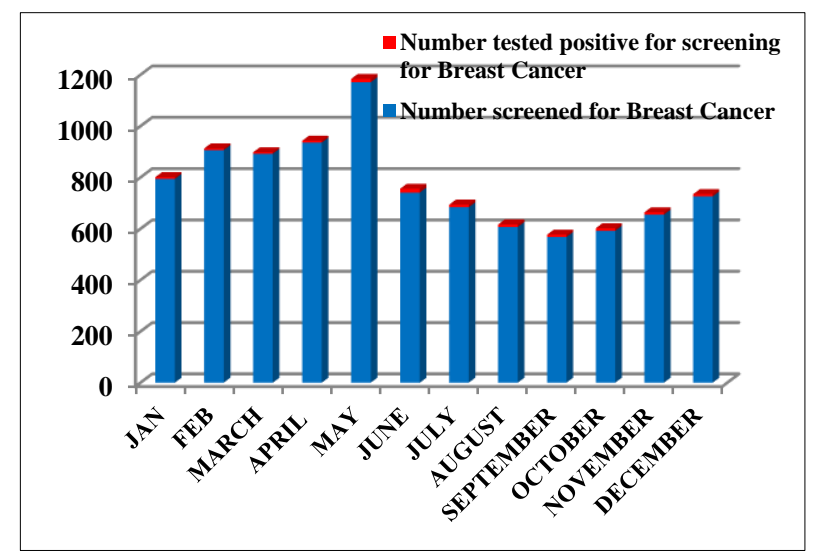

Figure 4: Screening for breast cancer - 2018.

More number of attendees in the first six months of the calendar year, from January to June. Authors observed a decline in the number from the month of July up till the month of September and an increase in the number from October to December (Figure 4).

In the screening for both breast cancer and cervical cancer, authors observed a decrease in the numbers screened in July, which continued till the month of September and then followed by a steady increase in the numbers of women screened, which was observed from 
the month of October and continued till the month of December. ${ }^{7,8}$

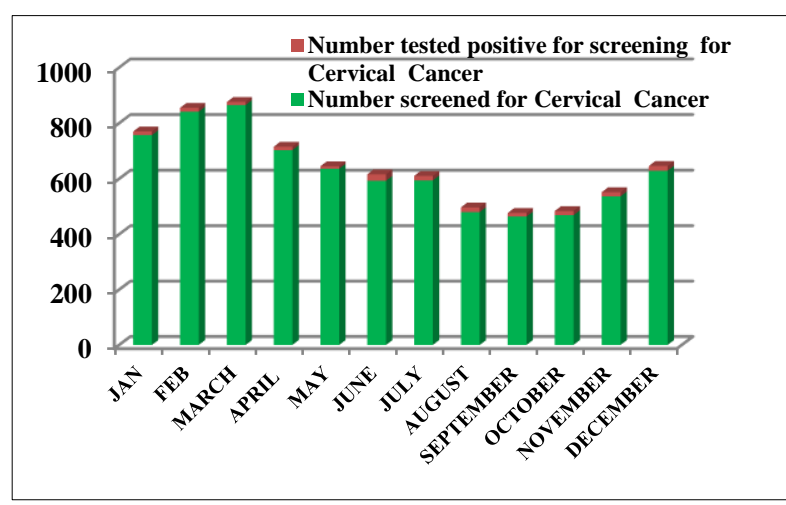

Figure 5: Screening for cervical cancer - 2018.

More number of attendees in the first three months of the calendar year, from January to March. Authors observed a decline in the number from the month of April which continued up till the month of September and followed by an increase in the number from October to December (Figure 5).

Numerous studies have been conducted across the globe which provided the proof that the screening policies for detecting diseases such as hypertension and diabetes mellitus, have a preventive impact on morbidity and mortality associated with the diseases. This is why evidence-based international recommendations have been issued for implementing screening policies, for detecting diseases such as hypertension and diabetes mellitus. 5,6

Early detection of disease and its management plays a key role in reducing the associated morbidity and mortality of diseases. ${ }^{9,10}$ The WHO has recommended the population-based screening for cervical and breast cancer. Educational model-based interventions promote self-care and create a foundation for improving the acceptance for cancer screening. ${ }^{11-14}$ Screening policies should take into consideration socio-economic factors, which influence disease causation. ${ }^{15}$ The introduction of innovative methods for screening of large population should be emphasized. Public awareness on early detection by screening should be encouraged. ${ }^{16,17}$

\section{CONCLUSION}

Of the total number of 42,519 women screened for common non communicable diseases - hypertension, diabetes mellitus, breast cancer and cervical cancer, nearly $5.55 \%$ women had positive results for screening tests done for any one of the diseases screened. The screening results at the NCD clinic in the study period revealed that, of the total number of women screened for hypertension, $8.7 \%$ of women had raised blood pressure; $7.31 \%$ of the total number of women screened for diabetes mellitus had raised blood sugar levels. Nearly $1.21 \%$ women had positive screening test results for breast cancer, $2.31 \%$ women had positive screening test results for cervical cancer. As per the NCD guidelines, women who tested positive for the screening tests for hypertension, diabetes mellitus and breast cancer were referred to the respective hypertension clinic, diabetes clinic or breast clinic, at the Govt. General hospital (RGGGH) and women with positive tests for cervical cancer screening were referred to Colposcopy cervical cancer screening clinic, in the same tertiary centre for further management.

\section{ACKNOWLEDGMENTS}

Authors would like to thank the Director, IOG for granting permission to conduct this study. The authors also thank Dr. DM Christe, NIRRH-FU, ICMR for her guidance in conducting this study.

\section{Funding: No funding sources}

Conflict of interest: None declared

Ethical approval: The study was approved by the Institutional Ethics Committee

\section{REFERENCES}

1. Thakur JS, Raina N, Karna P, Singh P, Jeet G, Jaswal N. Overview of national strategies on noncommunicable disease and adolescent health in South-East Asia Region countries. Int $\mathrm{J}$ NonCommun Dis. 2016;1:76-86.

2. Sharma A. Global research priorities for noncommunicable diseases prevention, management, and control. Int J Non-Commun Dis. 2017;2:107-12

3. Kathirvel S, Thakur Rapporteurs JS. Sustainable development goals and non-communicable diseases: Roadmap till 2030 - A plenary session of world non communicable diseases congress 2017. Int J nonCommun Dis. 2018;3:3-8.

4. Mahipala P, Dorji G, Tisocki K, Rani M. A critical review of addressing cardiovascular and other noncommunicable diseases through a primary health care approach in the South-East Asia Region. Cardiovasc Diagn Ther. 2019;9(2):150-7.

5. Tripathy JP. Partnerships in non-communicable disease prevention and control. Int $\mathbf{J}$ Non-Commun Dis. 2017;2:102-6.

6. Low W, Lee Y, Samy AL. Non-communicable diseases in the Asia-Pacific region: prevalence, risk factors and community-based prevention. Int $\mathbf{J}$ Occup Med Environ Health. 2015;28(1):20-6.

7. Doubeni CA, Gabler NB, Wheeler CM, McCarthy AM, Castle PE, Halm EA. Timely follow-up of positive cancer screening results: A systematic review and recommendations from the PROSPR Consortium. CA Cancer J Clin. 2018;68(3):199-216.

8. SaeiGhareNaz M, Simbar M, RashidiFakari F, Ghasemi V. Effects of model-based interventions on breast cancer screening behavior of women: a systematic review. Asian Pac J Cancer Prev. 2018;19(8):2031-41. 
9. Christe DM, Chandrasekar A, Jayashree K, Meenalochani P, Gunasingh STK. Prevention of cervical cancer: early detection of precancerous lesions of cervix in women from a marginalized environment. Int $\mathrm{J}$ Reprod Contracept Obstet Gynecol. 2018;7(12):5156-61.

10. Christe DM, Kanchana MP. Impact of cervical cancer screening in a referral centre. J Pharm Biomed Sci. 2016;06(06):360-2.

11. Christe DM, Kanchana MP, Sheelaa W. Recent changes in incidence of cervical cancer in a gynecologic cancer treatment center Chennai, India. J Hosp Pharma. 2019;14:4.

12. Christe DM, Mohanambal M, Ramamoorthy V, Snehaa NB. A study of cervical cancer screening for prevention of carcinoma cervix. J Indian Med Assoc. 2008;106(12):779-82.

13. Srivastava AN, Misra JS, Srivastava S, Das BC, Gupta S. Cervical cancer screening in rural India: Status and current concepts. Indian J Med Res. 2018;148(6):687-96.
14. Sauvaget C, Fayette JM, Muwonge R, Wesley R, Sankaranarayanan R. Accuracy of visual inspection with acetic acid for cervical cancer screening. Inter $\mathbf{J}$ Gynecol Obstet. 2011;113:14-24.

15. Gaffney DK, Hashibe M, Kepka D, Maurer KA, Werner TL. Too many women are dying from cervix cancer: problems and solutions. Gynecol Oncol. 2018;151(3):547-54.

16. Yang H, Zhang X, Hao Z. The diagnostic accuracy of a real-time optoelectronic device in cervical cancer screening: A PRISMA-compliant systematic review and meta-analysis. Medicine (Baltimore). 2018;97(29):e11439.

17. Dillner J. Early detection and prevention. Mol Oncol. 2019;13(3):591-8.

Cite this article as: Christe DM, Vijaya $\mathrm{S}$, Tharangini K. Screening for non-communicable diseases. Int J Reprod Contracept Obstet Gynecol 2020;9:1092-6. 